\title{
NILAI EKONOMI MANFAAT BIOGAS PADA RUMAHTANGGA PETERNAK SAPI PERAH: Survey di Desa Haurngombong Kecamatan Pamulihan Kabupaten Sumedang
}

\author{
Andre R. Daud \\ Pengajar di Laboratorium Ekonomi Ternak \\ Fakultas Peternakan Universitas Padjadjaran \\ e-mail: daud.andre@gmail.com
}

\begin{abstract}
ABSTRAK. Penelitian ini bertujuan terutama untuk mengetahui nilai manfaat ekonomi biogas pada rumahtangga peternakan. Sebanyak 45 rumahtangga peternakan di wilayah penelitian dijadikan rumahtangga contoh. Nilai manfaat ekonomi biogas diperhitungkan dengan menggunakan pendekatan pangsa biaya konsumsi energi, yang kemudian dimodelkan secara ekonometrik dengan teknik estimasi OLS. Hasil perhitungan menunjukkan bahwa penggunaan biogas sebagai alternatif bahan bakar secara nyata dapat menurunkan pangsa biaya konsumsi energi rumahtangga sebesar $52,2 \%$, dimana penurunan tersebut setara dengan nilai sebesar Rp. 133,000 per bulan.
\end{abstract}

Kata kunci: biogas, nilai ekonomi, rumahtangga peternakan, pangsa biaya.

\section{THE ECONOMIC VALUE OF BIOGAS IN DAIRY HOUSEHOLDS: Survey at Haurngombong Village, sub-District Pamulihan District Sumedang}

ABSTRACT. This study aims primarily to determine the economic value of biogas in dairy households. A total of 45 households in the study area used as sample. The economic value of biogas are calculated using energy budget share within household's total income, which is then modeled in econometrics with OLS estimation technique. The result shows that the use of biogas as an alternative fuel can significantly lower the share of energy cost by $52.2 \%$, where the decline is equivalent to the value of Rp. 133.000 per month.

Keywords: biogas, economic value, dairy household, budget share.

\section{PENDAHULUAN}

Teknologi gasifikasi limbah ternak untuk menghasilkan methan $\left(\mathrm{CH}_{4}\right)$ yang dapat digunakan sebagai sumber energi sudah dikenal sejak lama (Darrow dan Rick, 1976). Meskipun begitu, proporsi jumlah rumahtangga pemanfaat biogas pada saat ini diyakini masih relatif sangat rendah dibandingkan dengan jumlah keseluruhan rumahtangga peternakan yang terdapat di Jawa Barat. Selain itu, 
dibandingkan dengan besarnya populasi ternak di Jawa Barat- khususnya ternak ruminansia besar - maka potensi pengembangan pemanfaatan biogas oleh rumahtangga lainnya diperkirakan masih sangat besar. Berkaitan dengan jumlah rumahtangga pemanfaat biogas, data-data menunjukkan bahwa tingkat kecepatan (akselerasi) pengembangan penerapan sistem biogas di Jawa Barat masih sangat rendah. Jika diasumsikan bahwa intensifikasi pengembangan penerapan biogas dilaksanakan pada tahun 2000-2001 (Nurhasanah et.al, 2005) maka kecepatan pengembangan tersebut hanya sekitar 100-150 unit per tahun. Jumlah ini tentunya cukup rendah jika dibandingkan dengan tingkat kecepatan pengembangan penerapan biogas pada negara-negara berkembang lainnya; dimana rata-rata pertambahan unit biogas dapat mencapai 600 unit per tahun. Merujuk pada kecepatan penambahan rumahtangga pemanfaat, tampaknya seluruh kegiatankegiatan tersebut belum dapat secara efektif mencapai tujuan yang diharapkan.

Terdapat berbagai faktor yang diperkirakan mendasari hal tersebut di atas. Salah satu faktor yang utama tentunya adalah pemanfaat sistem biogas itu sendiri (rumahtangga peternakan). Sebagai salah satu bagian dari teknologi pengolahan limbah ternak, maka penerapannya juga sangat dipengaruhi terutama oleh sistem sosial-ekonomi yang dimiliki oleh setiap rumahtangga pemanfaat biogas dan lingkungannya masing-masing. Di dalam konteks ini, suatu teknologi akan dengan mudah diadopsi oleh rumahtangga jika penggunaannya akan menghasilkan benefit bagi rumahtangga tersebut, baik pada aspek sosial (intangibles) atau pun ekonomi (tangibles). Oleh karena itu, penelitian ini bertujuan terutama untuk mengetahui nilai ekonomi manfaat biogas pada rumahtangga peternakan di wilayah penelitian. Perkiraan nilai manfaat ekonomi biogas dilakukan dengan pendekatan pola biaya rumahtangga (household expenditure); yaitu pendekatan yang melihat hubungan antara tingkat pendapatan rumahtangga dan pangsa biaya konsumsi, atau dikenal sebagai kaidah / hukum Engel (Deaton dan Muellbauer, 1980). Pada penelitian ini, biaya konsumsi energi secara agregat menjadi proksi utama di dalam memperkirakan nilai ekonomi biogas. Pada prinsipnya, nilai ekonomi biogas akan diperoleh dari koefisien pembeda pangsa biaya konsumsi energi pada sebelum dan sesudah suatu rumahtangga peternak menggunakan biogas sebagai alternatif sumber energi. Konsumsi energi rumahtangga peternak mencakup energi panas (inflammable) dan energi listrik, dimana biogas merupakan bahan bakar untuk menghasilkan energi panas. Oleh karena itu, pada prinsipnya, nilai ekonomi biogas dapat diderivasi dari kemampuannya untuk mensubstitusi bahan bakar konvensional (kayu bakar, minyak tanah dan gas LPG) yang lazim digunakan oleh rumahtangga peternak sebagai sumber energi panas.

\section{METODE}

Penelitian ini dilakukan di Desa Haurngombong Kecamatan Pamulihan Kabupaten Sumedang, selama periode bulan Maret sampai dengan Juni 2009. Pertimbangan utama di dalam memilih wilayah penelitian ini adalah cukup banyak terdapatnya rumahtangga peternakan yang telah menggunakan biogas sebagai 
alternatif sumber energi. Di wilayah tersebut, terdapat 48 rumahtangga peternak pengguna biogas, sehingga di dalam penelitian ini, 45 rumahtangga dipilih secara sengaja (purposive) sebagai contoh (sample) dengan harapan dapat mewakili populasi. Keseluruhan rumahtangga contoh merupakan sumber data primer yang diperoleh melalui wawancara dengan menggunakan daftar pertanyaan terstruktur. Model yang digunakan untuk menganalisis nilai ekonomi biogas adalah fungsi konsumsi Engel, dengan persamaan fungsional sebagai berikut:

(1) $q_{i}=f_{i}(y, z)$;

dimana $q_{i}$ adalah jumlah barang yang dikonsumsi, $y$ adalah pendapatan atau total biaya rumahtangga, dan $z$ adalah vektor shifter (karakteristik lainnya). Di dalam operasionalisasi penggunaannya, barang yang dimaksud pada persamaan (1) lebih lanjut dapat dituliskan sebagai:

(2) $w_{i}=g_{i}\{\ln (y), z\}$.

dimana $w_{i}$ adalah pangsa biaya (budget share) konsumsi rumahtangga secara agregat. Penggunaan pangsa biaya lazim digunakan sebagai proksi dari jumlah barang yang dikonsumsi (persamaan (1)) karena pada umumnya rumahtangga mengkonsumsi barang yang bersifat bundle serta mengikuti kaidah non / weakseparability (Chern et.al, 2003). Berdasarkan ini, perkiraan nilai ekonomi biogas dapat dituliskan dengan persamaan estimasi dilinierkan berikut ini:

(3) $\frac{S E C}{T_{I N}}=\beta_{0}+\beta_{1 i} \ln T I N+e_{i}$;

di mana SEC adalah pangsa biaya konsumsi energi rumahtangga i (dalam Rp), TIN adalah total pendapatan rumahtangga (dalam $\mathrm{Rp}$ ) dan e adalah error term. Melalui persamaan (3) maka akan diperoleh parameter pangsa konsumsi energi di setiap rumahtangga contoh. Elastisitas pangsa biaya energi juga dapat diperoleh dengan menggunakan parameter tersebut, dengan cara (Alston et.al, 1994; Park et.al, 1996):

(4) $e_{i}=\frac{\beta_{1 i}}{S E C / T I N}+1$.

Untuk mendapatkan parameter nilai ekonomi biogas, maka persamaan (3) dapat dimodifikasi menjadi:

(5) $\frac{S E C}{T_{I N}}=\beta_{0}+\beta_{1 i} \ln T I N+\delta_{i} D+e_{i} ;$

di mana $D$ adalah variabel dummy yang bernilai 1 dan 0 , yang menunjukkan periode waktu penggunaan biogas pada rumahtangga, yaitu sebelum dan sesudah biogas digunakan oleh rumahtangga contoh, yang kemudian dihitung dengan cara sebagai berikut:

(6) $N E B=\frac{S E C}{T I N} \cdot\left(\sum \beta_{i}+\delta_{i}\right)$;

di mana $N E B$ adalah nilai ekonomi biogas. Persamaan (5) akan diestimasi dengan menggunakan metode ordinary least squares (OLS) dengan asumsi varians errror terbatas dan kondisi homoskedastis terpenuhi (Gao et.al, 1994; Nayga, 1995). Estimasi dilakukan dengan menggunakan perangkat lunak Stata versi 10. 


\section{HASIL DAN PEMBAHASAN}

Di wilayah penelitian terdapat 179 rumahtangga peternak sapi perah, dengan populasi sapi mencapai 771 ekor pada berbagai umur. Rerata jumlah sapi perah yang diusahakan oleh setiap rumahtangga mencapai 6 ekor, meskipun begitu, rerata sapi perah laktasi (produktif) pada saat penelitian ini dilaksanakan hanya mencapai 3 ekor per rumahtangga. Di antara seluruh rumahtangga peternak tersebut, hanya terdapat $48(27 \%)$ rumahtangga yang memanfaatkan limbah peternakan untuk diolah lebih lanjut sebagai bahan baku penghasil biogas. Distribusi rumahtangga pengguna biogas di wilayah penelitian, di desa Haurngombong, dapat disajikan pada tabel berikut ini.

Tabel 1. Rumahtangga peternak pengguna biogas.

\begin{tabular}{lc}
\hline Lokasi domisili di Ds. Haurngombong & Jumlah rumahtangga \\
\hline Kp. Pangaseran & 7 \\
Kp. Cipareuag & 4 \\
Kp. Simpang & 11 \\
Kp. Sekepaku & 6 \\
Kp. Pamulihan & 17 \\
\hline & Jumlah \\
\hline
\end{tabular}

Sumber: data primer.

Secara umum, rumahtangga contoh memiliki perilaku yang sama di dalam melakukan kegiatan konsumsinya. Di dalam konteks ini, konsumsi dibedakan menjadi konsumsi pangan, bukan-pangan, dan energi. Konsumsi pangan merupakan bundle dari makanan pokok, makanan penyela, juga termasuk makanan kecil dan rokok, yang lazim dikonsumsi oleh anggota rumahtangga. Konsumsi non pangan mencakup sandang, pendidikan, transportasi dan lainnya. Sementara konsumsi energi mencakup penyediaan bahan bakar yang terdiri dari kayu bakar, minyak tanah, dan gas LPG. Besaran biaya masing-masing jenis konsumsi pada rumahtangga contoh disajikan di bawah ini.

Tabel 2. Alokasi biaya konsumsi pada rumahtangga contoh.

\begin{tabular}{lcc}
\hline \multicolumn{1}{c}{ Jenis Konsumsi } & Biaya Rata-rata $(\mathrm{Rp})$ & $\%$ dari Total Pendapatan \\
\hline Pangan & 716,616 & 26.4 \\
Bukan-pangan & 394,383 & 14.5 \\
Energi & 254,102 & 9.4 \\
\hline Konsumsi Total & $1,365,101$ & 50.3 \\
Bukan-konsumsi & $1,346,755$ & 49.7 \\
\hline Pendapatan & $2,711,856$ & 100.0 \\
\hline
\end{tabular}

Sumber: data primer. 
Salah satu komponen biaya yang jelas terlihat pada tabel di atas adalah cukup besarnya pangsa biaya untuk komponen "bukan konsumsi". Tidak seperti rumahtangga pada umumnya yang diasumsikan sebagai konsumen, rumahtangga pertanian / peternakan juga merupakan entitas produksi (Nicholson, 2004). Dengan itu, cukup besarnya biaya bukan konsumsi, yang sebagian besarnya digunakan sebagai biaya produksi ternak, dapat dijustifikasi di dalam penelitian ini. Pangsa biaya konsumsi energi pada rumahtangga contoh tercatat mencapai ratarata $9,4 \%$ dari total pendapatan rumahtangga peternak, bervariasi dari $2 \%$ sampai dengan $26 \%$. Secara nominal, biaya konsumsi energi bervariasi untuk setiap rumahtangga contoh, dengan kisaran. antara Rp. 37.500 sampai dengan Rp. 570.000 per bulan, dengan rata-rata mencapai Rp. 254,000 per bulan. Pada saat penelitian ini dilaksanakan, secara empiris dapat diamati bahwa biaya energi merupakan biaya yang harus dikeluarkan oleh rumahtangga untuk membeli bahan bakar yang mencakup kayu bakar, minyak tanah dan gas LPG.

Berdasarkan hasil pengamatan, energi dapat diasumsikan sebagai barang kebutuhan pokok (necessities) bagi rumahtangga contoh. Hal ini juga sesuai dengan yang dikemukakan oleh penelitian yang dilakukan oleh Sun (1996), yang menunjukkan bahwa elastisitas permintaan rumahtangga atas energi adalah sebesar kurang dari satu $(E>1)$. Oleh karena itu, sebagai barang kebutuhan pokok, pangsa biaya konsumsi energi juga akan mengikuti kaidah Engel. Kaidah tersebut menyatakan bahwa pangsa biaya konsumsi barang pokok akan semakin rendah sejalan dengan kenaikan tingkat pendapatan rumahtangga (Deaton dan Muellbauer, 1980). Sesuai dengan kaidah tersebut, pangsa biaya energi relatif terhadap tingkat pendapatan rumahtangga contoh dapat secara empiris digambarkan pada gambar $1 .$.

Seperti yang terlihat pada gambar 1, pangsa biaya energi yang harus dikeluarkan oleh rumahtangga contoh cenderung semakin rendah sejalan dengan semakin tingginya tingkat pendapatan. Hal ini menunjukkan bahwa biaya konsumsi energi akan secara signifikan membebani rumahtangga dengan tingkat pendapatan yang relatif rendah, sementara sebaliknya dengan rumahtangga peternak berpendapatan tinggi. Temuan empiris tersebut dapat menunjukkan bahwa terdapatnya sumber energi alternatif bagi rumahtangga akan secara nyata menurunkan pangsa biaya konsumsi energi. Pada faktanya, penggunaan biogas sebagai energi alternatif belum dapat sepenuhnya menjadi substitusi bagi energi konvensional yang digunakan oleh rumahtangga pada saat ini. Namun dapat diamati, penggunaan biogas secara nyata dapat menghasilkan penghematan nominal di dalam struktur biaya energi secara keseluruhan. 


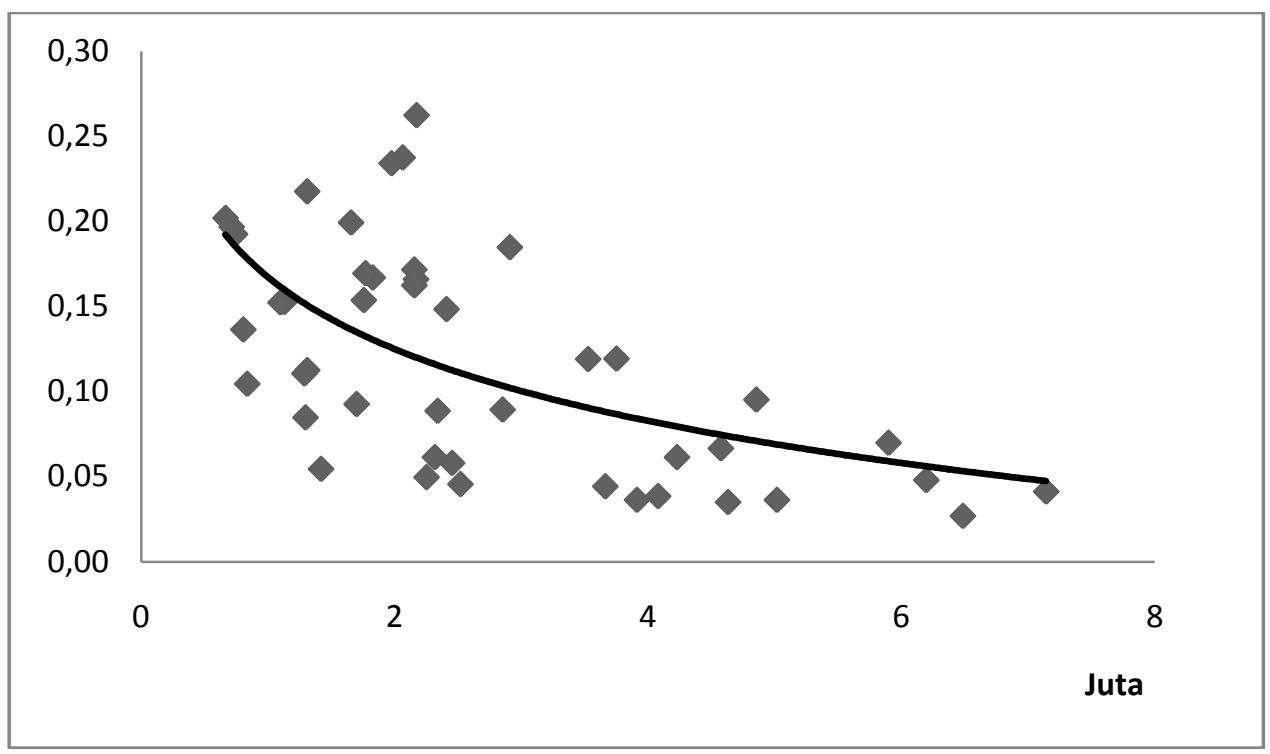

Gambar 1. Pangsa biaya energi dan tingkat pendapatan rumahtangga.

Ket.: sumbu Y (vertikal) mewakili pangsa biaya energi, sumbu X (horisontal) mewakili tingkat pendapatan rumahtangga (dalam juta rupiah).

Berdasarkan temuan di atas, nilai ekonomi biogas dapat diasumsikan sebagai nilai penghematan yang dapat dihasilkan oleh rumahtangga dalam menggunakan biogas. Hal ini juga yang digunakan di dalam model estimasi yang telah dispesifikasi sebelumnya. Hasil perhitungan pada model tersebut dapat disajikan di bawah ini.

Tabel 3. Hasil estimasi model konsumsi energi rumahtangga.

\begin{tabular}{lccc}
\hline & Konstanta & Pendapatan & Dummy \\
\hline Nilai koefisien & 0.692 & -0.090 & -0.080 \\
SE variabel & 0.109 & 0.017 & 0.009 \\
t Stat & 6.359 & -5.287 & -8.644 \\
P-value & 0.000 & 0.000 & 0.000 \\
\hline R Square & 0.541 & & \\
SE model & 0.044 & & \\
Sig. F & 0.000 & & \\
\hline
\end{tabular}

Secara umum, model yang dispesifikasi pada penelitian ini cukup rasional berdasarkan tanda dan besarannya. Sesuai dengan landasan kaidah Engel, tanda minus (-) pada koefisien pendapatan dan dummy menunjukkan bahwa kenaikan 
tingkat pendapatan rumahtangga akan direspon dengan turunnya pangsa biaya energi di dalam rumahtangga tersebut. Sementara tanda koefisien dummy menunjukkan bahwa terdapat perbedaan yang nyata pada pangsa biaya energi pada saat sebelum dan sesudah digunakan, dimana terjadi penurunan pangsa biaya energi setelah rumahtangga contoh menggunakan biogas sebagai energi alternatif. Variasi pada variabel pangsa biaya energi dapat dengan baik diterangkan oleh variasi pada variabel tingkat pendapatan rumahtangga, yang ditunjukkan oleh nilai keeratan hubungan (R2) sebesar 54,1\%, sementara variasi lainnya tidak dapat ditangkap oleh model. Sebagaimana biaya konsumsi energi merupakan sebagian dari biaya konsumsi lainnya, maka variasi yang terjadi pada pangsa biaya konsumsi lainnya dapat menjustifikasi nilai keeratan hubungan di dalam model.

Nilai koefisien pendapatan menunjukkan bahwa setiap kenaikan pendapatan rumahtangga peternak sebesar $10 \%$ akan menyebabkan pangsa biaya konsumsi energi pada rumahtangga tersebut cenderung mengalami penurunan sebesar 6,1\% (lihat Persamaan 4 dan Gambar 1). Pada nilai koefisien dummy, besaran dan nilai statistik $P$ menunjukkan bahwa terdapat perbedaan yang nyata pada pangsa biaya konsumsi energi antara pada saat sebelum dan sesudah rumahtangga menggunakan biogas. Perbedaan tersebut ditunjukkan dari tanda koefisien negatif (-) yang berarti bahwa pada saat rumahtangga peternak menggunakan biogas maka secara nyata terjadi penurunan pangsa biaya konsumsi energi. Dengan menggunakan persamaan (6) maka besaran penurunan pangsa biaya energi setelah biogas digunakan oleh rumahtangga adalah sebesar $52.2 \%$ dari rata-rata pangsa biaya energi sebelumnya. Maka dengan menggunakan nilai estimasi ini, besaran nominal nilai penghematan / nilai ekonomi biogas adalah setara dengan Rp. 133,000 per bulan.

\section{SIMPULAN}

Berdasarkan hasil analisis, pemanfaatan biogas oleh rumahtangga peternak sapi perah di lokasi penelitian secara nyata telah menghasilkan kontribusi terhadap peningkatan ekonomi rumahtangga. Secara finansial, pemanfaatan biogas tersebut mampu mensubstitusi biaya energi sebesar Rp. 133,000 per bulan. Nilai ekonomi tersebut diperoleh dalam bentuk nilai penghematan terhadap biaya energy yang lazim dibayarkan oleh rumahtangga tersebut di dalam rentang waktu satu bulan.

Nilai manfaat ekonomi biogas sebagai alternatif bahan bakar yang lazim digunakan oleh rumahtangga contoh di wilayah penelitian tampaknya relatif cukup besar, yang ditunjukkan dari dari besarnya penurunan pangsa biaya konsumsi energi. Namun begitu, penelitian ini tidak memperhitungkan aspek investasi, biaya pemeliharaan perangkat pengolah limbah dan biaya tenaga kerja pengolah limbah. Berdasarkan berbagai laporan, terutama di wilayah sentra peternakan lainnya, nilai/manfaat ekonomi yang dihasilkan oleh biogas belum mampu menjadi insentif bagi rumahtangga peternak untuk secara berkesinambungan mengolah limbah ternak menjadi biogas. Hal ini mengindikasikan bahwa biaya yang dibutuhkan 
untuk menghasilkan biogas masih lebih besar daripada manfaat yang diperoleh. Oleh karena itu, manfaat ekonomi biogas tidak hanya diperoleh dari kemampuannya untuk menghasilkan substitusi bahan bakar, melainkan juga kemampuannya untuk menghasilkan produk sampingan berupa pupuk kandang. Jika nilai pupuk kandang juga disertakan di dalam analisis, baik manfaat tangibles atau pun intangibles, maka nilai manfaat ekonomi biogas diperkirakan meningkat secara signifikan.

\section{DAFTAR PUSTAKA}

Alston, J.M., Foster, K.A. dan Green, R.D. 1994. Estimating Elasticities with the Linear Approximate Almost Ideal Demand Systems. Economic Letters 71 : 351-56.

Chern, W.S., Ishibashi, K., Taniguchi, K., dan Yokoyama, Y. 2003. Analysis of Food Consumption Behavior by Japanese Households. FAO Economic and Social Development Paper. Vol.152.

Deaton, A. dan Muellbauer, J. 1980. An Almost Ideal Demand System. American Economics Review 70 : 312-336.

Deaton, A. dan Muellbauer, J. 1980. Economics and Consumer Behavior. Cambridge Univ. Press. Cambridge.

Gao, X.M., dan Spreen, T. 1994. A Microeconometric Analysis of U.S. Meat Demand. Canadian Journal of Agricultural Economics 42 : 397-412.

Nayga, R. M., Jr. 1995. Microdata Expenditure Analysis of Disaggregate Meat Products. Review of Agricultural Economics 17 : 275-85.

Nicholson, C.F, P.K Thornton dan R.W. Muninga. 2004. Household-level Impacts of Dairy Cow Ownership in Coastal Kenya. Journal of Agricultural Economics. Vol. $55(2)$

Nurhasanah, A., T.W.Widodo, Asari, E.Rahmarestia. 2005. Perkembangan Digester Biogas di Indonesia (Studi Kasus di Jawa Barat dan Jawa Tengah). Laporan Tahunan Tahun 2005. Balai Besar Pengembangan Mekanisasi Pertanian. Serpong.

Park, J. L., Holcomb, R.B., Raper, K.C. dan 0. Capps, Jr. 1996. A Demand Systems Analysis of Food Commodities by U.S. Households Segmented by Income. American Journal of Agricultural Economics 78 : 290-300.

Sun, J.W. 1996. Real Rural Residential Energy Consumption In China.Energy Policy. Vol. 24, No. 9, pp. 827-839. 